\title{
Desnaturalizar a técnica: contribuições feministas para pensar a direção de fotografia cinematográfica
}

//////////// Marina Cavalcanti Tedesco ${ }^{1}$

1. Doutora em Comunicação e Professora do PPG em Estudos Contemporâneos das Artes da Universidade Federal Fluminense. E-mail: ninafabico@yahoo.com.br. 
Resumo A direção de fotografia cinematográfica é entendida, geralmente, como uma área técnica, o que para muitos é sinônimo de neutra. Talvez por isso ainda não tenha merecido muita atenção dentro dos estudos sobre cinema e audiovisual. Porém, como toda técnica, ela foi desenvolvida a partir de determinados pressupostos e para atingir objetivos específicos. Neste estudo, pretendemos analisá-la a partir de uma perspectiva feminista a fim de identificarmos as visões de gênero que contribuíram para conformá-la, e que passaram a ser por ela impactadas. Faremos isso através do estudo de diversos manuais de cinematografia produzidos desde os anos 1930 e da confrontação de suas prescrições com filmes emblemáticos do cinema mexicano clássico industrial.

Palavras-chave Direção de fotografia, gênero, técnica.

Abstract Cinematography is generally understood as a technological area, which means neutral for many people. This may account for not deserving the due attention into the cinema and the audiovisual studies. However, as any technique, it was developed starting from some hypotheses to reach specific objectives. In this study, we aim to analyze it with a feministic perspective to identify the gender views that contributed to its expression, which were influenced by it. We'll do that by the sudy of some cinematographic manuals edited since the years 1930, comparing their guidelines with some important classic/industrial Mexican films.

Keywords Cinematography, gender, technique. 
Podemos identificar nas reflexões feministas sobre o cinema e o audiovisual três grandes tendências. A primeira delas teve em Prazer visual e cinema narrativo seu marco fundador. Neste ensaio, publicado no início dos anos 1970, Laura Mulvey se apropria do instrumental fornecido pela psicanálise com o objetivo de destrinchar a codificação do erótico realizada pelo patriarcalismo dominante no cinema hegemônico em Hollywood e "chamar a atenção para o modo como as preocupações formais desse cinema refletem as obsessões psíquicas da sociedade que o produziu" (MULVEY, 2003, p. 439).

Segundo a autora, em tal produção o olhar/a ação/o componente ativo (não só dos personagens, e sim do dispositivo de forma geral) seriam sempre masculinos e aquilo que é olhado/que sofre a ação/ que é passivo, femininos. "O homem controla a fantasia do cinema e também surge como o representante do poder num sentido maior: como o dono do olhar do espectador" (MULVEY, 2003, p. 445). Devido às muitas críticas que recebeu, Mulvey reviu suas posições, complexificando o esquema anteriormente proposto e operando de forma menos binária - caminho trilhado, também, por teóricos e teóricas de várias partes do mundo.

A segunda grande tendência das reflexões feministas sobre o cinema e o audiovisual consiste no estudo das representações da mulher no cinema clássico hollywoodiano. Com o passar dos anos surgiram investigações sobre a construção do feminino em outras cinematografias e nos cinemas moderno e contemporâneo. No entanto, é inegável que o período clássico de Hollywood continua sendo um objeto privilegiado para este tipo de estudo. 
Teresa de Lauretis (2003) avalia que muitas análises sobre a representação da mulher estão baseadas em visões estereotipadas e supõem que as mensagens são significativas por si sós e serão recebidas da mesma forma pelo público, independentemente de variáveis importantes, como gênero, classe, raça, sexualidade, geração, etc. Trata-se de um problema que pode ser encontrado tanto em obras de décadas atrás quanto em algumas redigidas nos dias de hoje.

Por fim, é preciso destacar que "ao lado desta releitura sexuada dos autores consagrados pela cinefilia [a qual podia se dar no nível do dispositivo semiótico e narrativo, no das representações de mulheres por eles construídas e na sua apropriação por espectadores e espectadoras que não fossem o homem branco heterossexual], outros trabalhos tornaram visíveis obras raras de realizadoras e que as histórias do cinema sistematicamente negligenciaram" (SELLIER, 2002).

Com isso, foram produzidas fontes de informação cujo valor é imensurável - no caso latino-americano, é preciso citar Realizadoras latinoamericanas/Latin American Women Filmmakers: cronologíal chronology (1917-1987), referência para qualquer pessoa que tenha interesse pelo tema. Tempos depois, passou-se a abranger outras áreas do processo de realização, como é o caso de Women behind the camera: conversations with camerawomen (1997), livro pioneiro sobre diretoras de fotografia, operadoras de câmera e assistentes de câmera mulheres.

Percebe-se que nenhuma das três grandes tendências das reflexões feministas sobre o cinema e o audiovisual privilegiou a técnica, embora ela venha, há anos, desempenhando um papel de destaque no pensamento feminista em geral. Donna Haraway, por exemplo, tomará os cyborgs como "um mapeamento ficcional da nossa realidade social e corporal, além de uma fonte imaginativa que sugere algumas associações muito frutíferas” (HARAWAY, 1994, p. 244) em sua tentativa de "construir um mito político irônico, fiel ao feminismo, ao socialismo e ao materialismo" (HARAWAY, 1994, p. 243). E os estudos feministas (assim como o movimento) reconheceram a importância da técnica para a moldagem e adequação da maternidade.

Visando a contribuir para o fim de tal lacuna desenvolvemos uma pesquisa cujos resultado principais apresentaremos nas próximas 
páginas. Seu ponto de partida foi a análise crítica das regras da "boa" direção de fotografia que vêm sendo transmitidas geração após geração através da convivência dos profissionais dos sets, de cursos livres, profissionalizantes e universitários, mas também de manuais de cinematografia. Em seguida, voltamos nossas atenções para algumas obras do cinema mexicano clássico industrial, uma cinematografia muito influenciada, mas em constante tensão com Hollywood onde tais regras foram gestadas e consolidadas. A confrontação do "como fazer" com a prática se fez necessária por entendermos que "uma técnica é nominalmente plena, absoluta, mas raramente é usada em sua plenitude. Cada ator a toma segundo uma maneira. Teoricamente, ela é plena; na prática não o é... Passamos do 'absoluto' irrealizado ao 'relativo' realizado” (SANTOS, 2006, p. 124).

\section{Sobre a forma "correta" de fotografar a mulher}

A partir do final dos anos 1910, Hollywood se tornou um polo irradiador para o cinema mundial não apenas no que tangia aos filmes que seriam exibidos nos mercados nacionais, mas também em relação às estrelas, técnicas, etc. A direção de fotografia não foi exceção. Produziu-se um consenso a respeito do modo supostamente mais adequado para construir a imagem dos atores e das atrizes, dentro do qual uma das perguntas fundamentais era: estamos fotografando um homem ou uma mulher?

Apesar de ser um saber (entendido aqui em termos foucaultianos) com quase um século de existência, após o estudo de entrevistas e memórias de importantes fotógrafos cinematográficos e de obras de caráter didático escritas e lançadas em diferentes décadas ficamos impressionados com o quanto ele permanece atual. A fim de demonstrarmos a referida continuidade conferiremos destaque no presente texto a Painting with light (do vencedor do Oscar de Melhor Fotografia de 1952 John Alton, publicada pela primeira vez em 1949) e 50 anos luz, câmera e ação (de autoria de Edgar Moura, cuja primeira edição data de 1999). A escolha de ambos se justifica tanto pela competência dos fotógrafos-autores como pela influência que suas obras exerceram. O livro de Moura é o mais completo sobre o tema redigido por um brasileiro, além de ser um dos poucos disponíveis em português. Já o de Alton é apontado por importantes diretores de fotografia (DF), como por exemplo 
Allen Daviau (apud McCARTHY, 1999 p. XXXIII-XXXIV), como fundamental em sua formação.

No que se refere à iluminação, é bastante comum que os DFs dediquem várias páginas de seus manuais ao mais clássico dos mapas de luz, conhecido como standard three-point lighting. Nele, o ataque tem a função de criar os claros e escuros que irão conferir a ilusão de tridimensionalidade, a compensação de auxiliar na obtenção dos níveis de contraste desejados e o contraluz de separar a personagem do fundo, glamourizar e, eventualmente, tornar visíveis chuva e fumaça.

Contudo, não é preciso se estender muito na leitura para que estas e outras regras gerais comecem a ser relativizadas. $\mathrm{O}$ ataque, por exemplo, pode ser desobrigado de produzir as altas luzes e as sombras densas que dão relevo àquilo que é iluminado (ou seja, de uma das principais razões de sua utilização por parte do diretor de fotografia) se incidir sobre uma mulher.

Nas noturnas, muitos fotógrafos se permitem atacar duro. Mas acabam deixando essa dureza para os homens. Para as atrizes sempre reservarão suas luzes mais delicadas. Nos filmes noir, chegava-se ao limite dessa técnica. Atacavam-se os atores com uma luz dura, de sombras marcadas, mas quando iluminavam as damas, usavam filtros difusores e sombras delicadas. Assim, aliás, exigiam os produtores dos grandes estúdios como Louis B. Mayer, o Mayer da Metro-GoldwinMaier, criador do sistema de estrelas da Metro. Mayer, ao contratar um fotógrafo alemão de filmes expressionistas, disse-lhe: "Sei que o senhor faz umas sombras maravilhosas. Continue assim, coloque suas sombras onde bem quiser, menos nos rosto das minhas atrizes" (MOURA, 2005, p. 116).

A proibição de projetar sombras sobre a face feminina está diretamente relacionada ao que é considerado importante nos homens e nas mulheres. Nas palavras de John Alton, "enquanto closes femininos ambicionam a beleza, nas imagens masculinas é o caráter do indivíduo que nós acentuamos" (ALTON, 1997, p. 96).

$\mathrm{E}$, se nos indivíduos associados à construção social denominada sexo feminino é a beleza que importa, é fundamental lembrarmos que esta beleza equivale à aparência da juventude, um padrão que se estabelece no audiovisual em Hollywood no final dos anos 1910. 
Desnaturalizar a técnica: contribuições feministas para pensar a direção de fotografia cinematográfical Marina Cavalcanti Tedesco

A exigência da beleza é simultaneamente a exigência de juventude... No cinema, até 1940, a idade média das estrelas femininas era de 20-25 anos, em Hollywood. Suas carreiras eram mais breves que as dos homens, que podiam não envelhecer, mas amadurecer até atingir a idade sedutora ideal (MORIN, 1989, p. 31).

É inegável que as fontes de luz direta, que não atravessam ou são rebatidas por algum obstáculo antes de chegarem até o motivo iluminado, produzem sombras nos baixos relevos, ou seja, nas rugas e linhas de expressão - pelo efeito visual que produzem são conhecidas como "duras". Para evitar que isso aconteça, alguns diretores de fotografia são extremamente rígidos e metódicos no momento de posicionar seus refletores.

[Para uma melhor compreensão de Alton observar a ilustração abaixo] Vamos pegar agora nossa luz de teste e colocá-la na posição de meio-dia, ainda no círculo A. Nós reparamos imediatamente como os poros da pele começam a desaparecer; nós estamos agora de fato retocando-a [a atriz] com a luz. Isso prova que o ataque mais lisonjeiro para closes femininos é sem dúvida o ataque frontal, um pouco acima da altura dos olhos. Um ataque frontal não equivale necessariamente a uma luz plana. Adicione um kicker na posição das 9:00, e um contraluz na posição do meio-dia, ambos no círculo C, e uma certa redondeza do rosto aparece; isso acentua a beleza... O ataque pode fazer um filme, mas é necessária iluminação adicional para fazê-lo extraordinariamente belo (ALTON, 1997, p. 94-95).

Figura 1 - o mapa de luz da beleza feminina por John Alton (Ilustração de Jamile Chalupe feita para esta pesquisa)

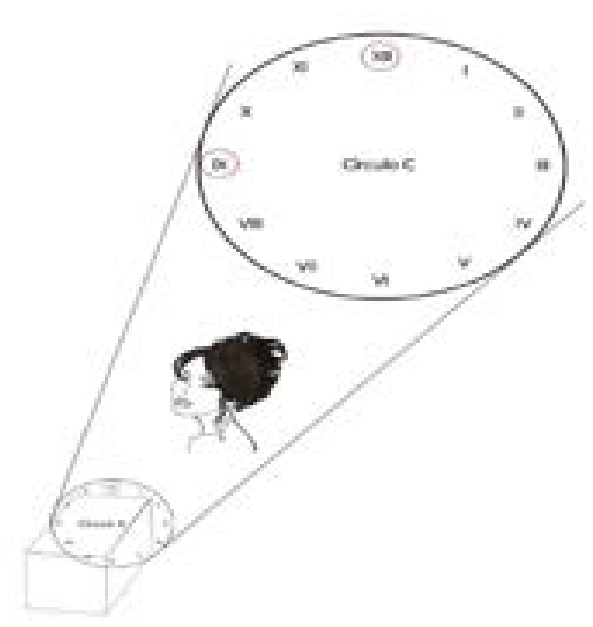


A iluminação adicional à qual John Alton faz referência é, muitas vezes, a compensação, necessariamente uma fonte de luz difusa (seja por reflexão ou filtragem), que, sem que percebamos sua presença, suaviza as áreas mais densas da imagem - e que, portanto, pode ser de grande utilidade para disfarçar as marcas do tempo na pele.

Tanto pelas características da luz que emite quanto pelo que pode contribuir para "melhorar" a imagem da mulher, é considerada a sua luz por excelência. O fotógrafo Edgar Moura afirma: "na compensação, não há penetração. É uma luz feminina, delicada. Pousa, não bate" (MOURA, 2005, p. 124). "A compensação é o brilho nos olhos dela" (MOURA, 2005, p. 65).

Isso não significa que nunca seja utilizada durante a captação da imagem dos homens - pelo contrário, em geral o é, especialmente se o personagem retratado for um mocinho ou se o gênero narrativo for mais "leve": uma comédia, um romance, um chick-flick. A forma como ela é trabalhada, contudo, muda de maneira radical em função de objetivos muitas vezes opostos. "As marcas no rosto de um homem são como as divisas de um soldado, são conquistadas. Elas significam caráter; portanto, nós não devemos tentar eliminá-las, uma vez que nos closes masculinos é exatamente isso que nós ambicionamos" (ALTON, 1997, p. 113).

O contraluz também pode fazer parte da iluminação adicional e, certamente, Alton, diretor de fotografia durante o auge do cinema clássico hollywoodiano, período em que o star system já estava consolidado e tinha um papel fundamental nas estratégias dos estúdios, pensava nele ao escrever. Esta terceira função da luz, recomenda-se, deve ser desempenhada por refletores tão ou mais potentes que aqueles empregados no ataque. Moura, todavia, identifica alguns poucos casos em que não se pode agir de tal forma.

Quando usar um contraluz difuso, porém, já que ele é normalmente duro e direto? Em dois casos: primeiro, quando ele for tocar no rosto da atriz... Quando esse contraluz, direto e duro, toca a face das atrizes, é uma catástrofe. Se essa luz tocar a bochecha da atriz, vinda assim, por trás e frisante, estará na sua pior direção e revelará volumes e relevos até então insuspeitados. Qualquer imperfeição na pele aparecerá como um caso para o dermatologista... Seu uso é mais necessário do que 
parece à primeira vista. Em muitos mais casos do que se pensa, é preciso sacrificar a força necessária ao contraluz em favor da beleza, indispensável à atriz (MOURA, 2005, p. 132-134).

Tratamos, até o momento, de demonstrar como a iluminação foi codificada e sistematizada também em função do gênero - um modo de compreendê-la que, a julgar pelo que encontramos durante a leitura de manuais contemporâneos, segue vigente. Infelizmente, não teremos espaço para abordar o restante do instrumental da fotografia em movimento (objetivas, filtros, etc.). Entretanto, gostaríamos de frisar que ele também se encontra regido pela mesma lógica, ao menos no nível da prescrição.

\footnotetext{
Durante o workshop, ele [Michael Hugo] filmou o retrato de uma mulher idosa usando uma pesada rede Dior preta... "A rede preta resolve o problema das rugas, acne e das outras imperfeições da pele. Porém, mesmo com uma rede pesada, você mantém a agudeza dos olhos. Eu usei a 'Dior' nos closes extremos de Joan Collins. Às vezes, quando eu não quero muita difusão, eu combino uma rede preta leve com um filtro fog de 1/8. Eu tento não me aproximar tanto, mas às vezes o diretor quer chegar muito, muito perto, mais perto do que se deveria chegar de qualquer mulher" (BERGERY, 2002, p. 65).
}

\section{Gestação e consolidação das prescrições para}

\section{a fotografia cinematográfica}

O surgimento de uma prática fotográfica que muitas vezes variava em função do gênero atendia tanto aos padrões de beleza então vigentes (ao mesmo tempo em que os reforçava) quanto a preceitos gerais os quais, cada vez mais, orientavam a construção da imagem cinematográfica.

Segundo Fabrice Revault D’Allonnes (1991), a fotografia gestada e consolidada em Hollywood entre a segunda metade de 1910 e o início dos anos 1930 se apoiava sobre o seguinte tripé: dramatização, hierarquização e visibilidade. Embora seja possível relacionar suas três "pernas" ao tema deste artigo, iremos concentrar nossas atenções na primeira delas, uma vez que a dramatização é a característica da 
fotografia cinematográfica clássica mais importante para o objeto aqui estudado.

Dramatizar consiste em trabalhar a luz de forma que ela seja "expressiva, retórica: dramatizada, psicologizada, metaforizada e eletiva. Que participe de um sentimento e de um sentido pleno e transparente (óbvio), ao contrário do mundo... Luz conotada, codificada” (D’ALLONNES, 1991, p. 7). Em outras palavras, deve-se, através da luz, tentar transmitir determinadas sensações/ informações para o espectador - embora nunca se tenha a certeza de que o objetivo será atingido.

Tomemos, por exemplo, o caso de Rebecca (Alfred Hitchcock, Estados Unidos, 1940). Na primeira vez em que a personagem de Joan Fontaine é atormentada por Rebecca, através de um sonho, há a projeção de uma sombra sobre ela que remete de forma bastante clara às grades de uma prisão. Depois de se tornar a nova Mrs. de Winter a situação se torna ainda pior. A protagonista não apenas se sente atormentada por Rebecca como também oprimida por Maxim de Winter e pela Mrs. Danvers, os quais projetam sombras sobre ela diversas vezes ao longo do filme. As projeções cessarão apenas com a mudança radical no comportamento da personagem, após esta descobrir a verdade sobre o casamento anterior de seu marido.

Léon Shamroy declara: "Um operador deve dramatizar"; Henri Alekan: "Não é a verdade da luz que eu procuro, é a revelação dos sentimentos"... Gordon Willis: "Filosoficamente, eu chamo este tipo de trabalho de realidade romantizada. Você não pode ser literal, você tem que reconstruir aquilo que está debaixo dos seus olhos tendo em vista um certo ponto de vista"; Vittorio Storaro: "Eu tento escrever a história do filme com a luz. Eu tento encontrar sua ideia principal e como ela pode ser representada de maneira simbólica, emocional, psicológica, realisticamente e fisicamente"; Giuseppe Rotunno: "O importante é a história e a sua atmosfera, seu sabor, seu odor. Uma coisa é o realismo. A verdade, para mim, é outra totalmente diferente. A verdade interior, pessoal, do cineasta, essa é a verdade" (D’ALLONNES, 1991, p. 12).

As prescrições para fotografar a mulher de forma "correta", portanto, não orientavam o diretor de fotografia a construir uma 
imagem suave, delicada, sem sombras densas e grandes contrastes apenas para que a pele de seus corpos e, em especial, rostos, ficasse para sempre jovem e livre de eventuais imperfeições. Elas pretendiam, também, construir uma visualidade em consonância com o ideal de feminilidade vigente, segundo o qual as mulheres - ou ao menos as "boas" mulheres, as mulheres "de verdade" - seriam frágeis, débeis, dependentes, emotivas e puras por natureza.

\section{O cinema mexicano clássico industrial e sua prática fotográfica}

Entre 1935 e 1955 o México produziu em média 72 longasmetragens por ano. Nesta pesquisa, concentramo-nos em seis deles, selecionados a partir dos seguintes critérios: 1) serem protagonizados por Dolores del Río ou María Félix, duas das maiores estrelas não apenas do cinema mexicano, mas do próprio cinema latino-americano à época; e 2) apresentarem diversidade nos papéis interpretados por ambas. Trata-se de uma quantidade pequena de filmes dentro de um universo muito grande e variado. Nosso objetivo, porém, nunca foi fazer generalizações válidas para toda a cinematografia do período, e sim refletir a respeito de alguns de seus elementos.

A primeira obra analisada foi Doña Bárbara (Fernando de Fuentes, México, 1943), que conta o embate entre Santos Luzardo, advogado que após anos morando em Caracas decide voltar a Altamira para recuperar a propriedade de sua família, e Doña Bárbara (María Félix), mulher que se convertera na dona e na lei da região.

Através de um flashback, o espectador é informado que há muitos anos La Doña fora vítima de uma tragédia que mudara sua vida. Moça doce, gentil e pura, viajava de barco por aquelas terras e estava apaixonada. Um dia, aproveitando-se da ausência do comandante da embarcação, os tripulantes assassinam seu amor e decidem através de um sorteio quem irá violá-la. Ao recuperar os sentidos após o estupro, Doña Bárbara não era mais a mesma. Tornara-se má, impiedosa, interesseira. Uma mulher que não apenas assumia o lugar dos homens, também os “devorava”.

Praticamente todo o tempo, a opção de Alex Phillips, diretor de fotografia estadunidense que durante muitos anos atuou no México, foi orientar sua atuação pela narrativa. No começo da história, mesmo submetida a um sol inclemente, María Félix estava sempre 
bem iluminada, apresentando detalhes em quase todas as áreas do rosto e sombras suaves - em uma fotografia que traduzia em termos visuais a bondade da personagem e, ao mesmo tempo, embelezava-a.

Depois, a dramatização do caráter "ruim” que emergiu e da transgressão dos papéis de gênero hegemônicos no cinema mexicano clássico industrial parece ter sido mais importante para a fotografia da protagonista. Do momento em que recobra a consciência em diante, sombras negras e ausência de mecanismos de suavização (como redes em frente à objetiva, filtros, vaselina, etc.) serão as características fotográficas de Doña Bárbara, ficando a luz difusa, as áreas pouco densas e a discreta falta de definição no rosto restritas à mocinha da história (sua filha Marisela).

Todavia, deve-se destacar que o modo supostamente mais adequado de se construir a imagem feminina não desaparece totalmente a partir de determinado ponto. Observa-se que muitas vezes as sombras que incidem sobre a face da atriz, provenientes dos cílios e do nariz, não são escuras como as demais, e que a supressão dos mecanismos de suavização é compensada por um trabalho de maquiagem que atenuava brilhos excessivos na pele ou linhas de expressão.

A segunda produção estudada foi La monja alférez (Emilio Gómez Muriel, México, 1944), que apresenta ao espectador a saga de Catalina de Erauso. Trancafiada em um convento após a morte do pai por uma tia interesseira, ela é obrigada a fugir, passar-se por homem e enfrentar enormes perigos em outro país para recuperar sua herança e amor.

Podemos afirmar que há em tal obra três tratamentos fotográficos no que tange à protagonista. O primeiro é destinado a María Félix (intérprete de Catalina) caracterizada como mulher. Apesar de ter sido uma menina com hábitos supostamente masculinos, tratase de uma jovem boa, casta e que sempre quis casar. Tamanha obediência aos seus sentimentos "típicos" e "normais" de mulher, aliada a um caráter inquestionável, correspondem a um respeito completo do diretor de fotografia às prescrições para se fotografar a mulher de forma "correta".

O segundo tratamento fotográfico de Catalina surge quando esta se traveste de homem. Diante de uma personagem que finge ser do sexo oposto, o DF tem pelo menos duas opções: 1) manter a 
fotografia "de mulher" até então utilizada (afinal, ela não age assim por vontade própria, e sim por força das circunstâncias, e o público sabe o tempo inteiro que é uma farsa); e 2) fotografar a atriz como "deve" ser fotografado um homem - ou seja, diminuir a difusão, aumentar o contraste e a densidade das sombras, etc. Raúl Martínez Solares escolhe a última alternativa.

O terceiro e último tratamento fotográfico é aplicado sobre María Félix apenas durante os episódios onde há "excesso de testosterona", ou seja, onde alguns homens tentam provar que são "mais homens" que os demais - através de duelos de espadas, principalmente. Aqui, a tradução visual da "macheza", da "honradez" e da "coragem extremas" - sempre justificadas e legitimadas - consiste em sombras ainda maiores e mais densas, e em uma diminuição, mas não ausência, dos mecanismos de suavização da face.

Percebe-se, por um lado, uma construção imagética orientada pelo gênero da personagem, variando de acordo com a performance homem ou mulher de Catalina. Ao mesmo tempo é impossível deixar de destacar que o travestismo da star mexicana, que dura a maior parte do filme, praticamente inviabiliza a análise nesses termos, tamanha é a rigidez e o binarismo com que trabalham as prescrições da fotografia cinematográfica - para as quais existem apenas dois sexos (homem e mulher), dois comportamentos (masculino e feminino) e uma orientação sexual (heterossexual) possíveis, que se entrelaçam de maneira "natural", aproblemática, sem espaço para outras possibilidades.

Em Río Escondido (Emilio Fernández, México, 1947), terceiro longa-metragem pesquisado, María Félix vive Rosaura, professora que recebe a missão de ensinar em Río Escondido, cidade distante da capital mexicana onde Don Regino é a lei. Mesmo sabendo das dificuldades que irá enfrentar e dos riscos que corre devido à truculência do cacique local e à sua frágil saúde, ela decide cumprir seu dever com a pátria sem se importar com o preço a ser pago.

Através desta rápida descrição, é possível perceber que Rosaura é bastante distinta de Doña Bárbara, a vilã que, embora permaneça mulher, comporta-se "como um homem", e de Catalina de Erauso, mulher boa, mas que precisa se passar por homem. Ela é professora de crianças (atividade associada com a mulher e algumas de suas características "naturais", em especial a "vocação" para a maternidade 
e a abnegação), coloca os interesses da nação em primeiro lugar, dedica sua vida aos ideais em que acredita. Ao mesmo tempo, não é uma mocinha fraca e indefesa que precisa sempre de um homem para socorrê-la, a quem é subserviente.

Todos os aspectos supracitados da personalidade da protagonista estão presentes na fotografia empreendida pelo mestre Gabriel Figueroa, o que gera uma visualidade complexa, a qual reforçar seu comportamento de moça boa, mas destemida.

Verifica-se certo nível de opacidade no sentido fotográfico quando analisamos a dramatização da narrativa. Ao chegar a Río Escondido, Rosaura descobre que a escola estava desativada, e é com muita dificuldade que ela e o médico Fernando logram reabri-la. Logo, seria de se esperar uma imagem "triunfal" do primeiro dia de aula. Não é o que acontece. Enquanto a professora faz a chamada, o lado esquerdo de seu rosto está mergulhado em uma grande sombra que, se ainda preserva informação, é estranhamente escura e torna bastante dramática uma situação que não o é. Reforça a sensação de estranhamento o desenho que a luz que entra pela janela projeta na roupa de Rosaura, o qual se assemelha a uma grade ou a espinhos.

Questionamo-nos se a quantidade e as características incomuns das áreas densas - que não se afastam apenas das prescrições para se fotografar a mulher de forma "correta", mas também dos códigos utilizados nas outras obras vistas até aqui para dramatizar um bom caráter ou um momento de vitória na narrativa - não são uma antecipação para o público de seu destino trágico. Uma pergunta que, evidentemente, ficará sem uma resposta conclusiva.

A quarta produção estudada foi María Candelaria (Emilio Fernández, México, 1943), que tem como protagonista uma mulher indígena cujo nome dá título ao filme, interpretada por Dolores del Río. Filha de uma prostituta assassinada por desonrar sua comunidade de origem, é impedida de viver entre os demais e de trabalhar, tendo apenas seu noivo, Lorenzo Rafael, e o padre local para defendê-la.

Como em diversos outros papéis vividos por del Río no México (que são muito diferentes dos de sua carreira estadunidense), María Candelaria não decide nada em sua vida: ou é levada pelos acontecimentos ou tem seus passos subsequentes traçados por outras pessoas, cabendo a ela apenas acatar o que foi estabelecido. Sua bondade, pureza, disponibilidade, passividade e castidade são tão 
singulares que em determinada sequência não apenas a fotografia, mas também a decupagem, a direção de arte e a direção de atores, irão sugerir para o espectador um paralelo entre ela e um dos grandes mitos mexicanos: a Virgem de Guadalupe.

Podemos afirmar que praticamente todo o tempo a indígena traz, inscritos em seu corpo, os códigos fotográficos reservados a boa parte das mocinhas do cinema mexicano clássico industrial. María Candelaria é iluminada por uma luz difusa e uniforme, de modo que as raras sombras produzidas são bastante discretas, tanto em densidade como em dimensões. As escassas altas luzes que chegam até seu rosto o fazem reluzir ao invés de brilhar. E sua imagem claramente é afetada por mecanismos de suavização.

Tudo converge para produzir a visualidade de uma mulher submissa, conformada às regras sociais, por mais injustas que sejam, e que precisa ser tutelada pelos homens. María Candelaria, como afirma o pintor do quadro que ocasionara sua morte, era "uma indígena de pura raça mexicana... [e] tinha a beleza das antigas princesas que foram subjugadas pelos conquistadores".

O único momento em que a fotografia da protagonista sofre uma drástica mudança é quando ela está em sua casa, ardendo em febre e delirando devido à malária que contraíra, sendo cuidada por um impotente e desesperado Lorenzo Rafael. As sombras densas, o brilho, a definição e o alto contraste que prevalecem nesta sequência tornam a ação ainda mais dramática, e contribuem para justificar as atitudes subsequentes e ilegais do noivo de María Candelaria.

Las abandonadas (Emilio Fernández, México, 1944), a quinta obra estudada, traz Dolores del Río como Margarita, uma jovem interiorana, pura e ingênua, que se casa com aquele que acreditava ser o homem de sua vida. Algumas semanas depois, ela descobre que tudo não passara de uma fraude. Seu marido, que até um nome falso inventara, tinha uma esposa na Cidade do México. Abandonada pelo esposo, renegada pela família e grávida, termina por migrar para a capital, onde tem seu filho e se integra ao alto meretrício.

Este será o drama de Margarita durante todo o filme: a despeito de seu bom caráter, as circunstâncias sempre acabam levando-a ao "mau caminho". Preserva sua virgindade até o matrimônio, e ainda assim se torna uma "mulher caída". Acredita ter encontrado um homem bom, que lhe oferecia a possibilidade de sustentar seu filho sem ter 
que recorrer à prostituição, e por isso amarga um longo período na cadeia. Responde a todos os anúncios de emprego, recebendo não como resposta.

A fotografia de Gabriel Figueroa acompanhará estes altos e baixos da protagonista. No primeiro close de Margarita, incide sobre seu rosto um ataque que só produz altas-luzes do lado direito de sua testa, nariz e bochechas. Uma compensação suave e uniforme garante informação mesmo nas zonas mais escuras e uma baixa relação de contraste. Ademais, é evidente a utilização de mecanismos de suavização da imagem.

Tal visualidade muda por completo quando todos descobrem que ela havia dormido com um "homem qualquer" - mesmo ficando claro que fora vítima de um golpe. Quem passa a ser registrada de acordo com o modo supostamente mais adequado de se construir a imagem feminina é a legítima esposa. Margarita se torna menos branca - e é importante lembrarmos que na cultura ocidental a branquitude está fortemente associada com a pureza, característica tida como fundamental nas mulheres. A densidade de suas sombras também aumenta consideravelmente. Na bochecha direita ainda há alguns poucos detalhes; já o contorno do lado esquerdo de seu pescoço se perde na escuridão.

Contudo, nem sempre a dramatização empreendida pelo DF terá um sentido óbvio, transparente - como já acontecera em Río Escondido. Quando Margarita conhece o general Juan Gómez, por exemplo, volta a ser fotografada como a virgem inocente que era no início da história (apesar de o casal ter se formado no bordel onde ela trabalhava).

O sexto e último longa-metragem pesquisado é La casa chica (Roberto Gavaldón, México, 1950). No México, "la casa chica" é a expressão utilizada para designar a outra casa dos homens, onde eles podem conviver tranquilamente com suas amantes - tratam-se, em geral, de relacionamentos muito duradouros e estáveis, próximos a um segundo casamento que ocorre em paralelo ao primeiro.

É exatamente este o caso de Amalia (Dolores del Río) e Fernando, que, devido a um golpe, acaba contraindo matrimônio com sua antiga noiva - o que condena o amor dos dois à ilegalidade eterna, posto que o divórcio não era uma possibilidade no cinema mexicano clássico industrial. 
Mesmo representando a falência da família burguesa, a amante é, em La casa chica e muitas outras produções do período, apresentada como uma pessoa boa, pura, abnegada e subserviente, "melhor" e mais "nobre" que a esposa legítima.

O tratamento fotográfico conferido a Amalia por Alex Phillips corresponde, quase o tempo todo, ao ideal hollywoodiano para a fotografia feminina. Com isso, o DF consegue tanto embelezar a atriz (de acordo com os padrões estéticos vigentes, claro), como dramatizar as características extremamente "desejáveis" da personagem (segundo o sistema de gênero hegemônico no cinema mexicano clássico industrial).

No primeiro plano em que a protagonista aparece, idosa, esperando o telefonema de seu amado - como fizera a vida inteira, informa a voz sobreposta -, a imagem de seu rosto está tão suavizada que as supostas rugas que ela deveria ter em decorrência da idade mal aparecem. Ademais, a luz que incide sobre a face é difusa e homogênea, a ponto de a sombra projetada pelo nariz ser quase imperceptível.

Há, ainda nesta produção, uma sequência bastante interessante para o tema aqui investigado. Um menino que passara por uma complicada cirurgia realizada em conjunto por Amalia, seu tio e Fernando, se recupera e volta a enxergar. O momento é de extrema felicidade e cada um deles é mostrado em close. A fotografia da mulher é muito mais próxima da fotografia da criança que da dos adultos (uma tradução visual da suposta natureza pura, ingênua e dependente de ambos?). Apenas a utilização dos mecanismos de suavização da imagem não foi a mesma. Em um claro exemplo da falta de interesse de boa parte da fotografia pela "realidade", o ator mirim apresenta linhas de expressão mais marcadas que Dolores del Río.

$\mathrm{Na}$ análise das seis obras fica evidente que, a despeito da grande influência exercida pelas prescrições hollywoodianas para se fotografar a mulher de forma "correta" no cinema mexicano clássico industrial, a prática fotográfica de tal cinematografia podia ser muito mais variada e complexa.

Em Doña Bárbara, María Félix interpreta uma vilã que é fotografada durante praticamente todo o tempo com desenhos de luz que produzem grandes e densas zonas negras em seu rosto, chegando-se a momentos extremos onde esforços são realizados para 
"enfeiá-la". Em La monja alferez, a visualidade de Félix corresponde à dos indivíduos associados à construção social denominada sexo masculino durante a (longa) parcela da narrativa em que simula ser um deles. E em Río Escondido, a bondosa, pura e abnegada professora de crianças vivida pela atriz apresenta uma imagem em muitos momentos inexplicavelmente desviante do padrão adotado pelo cinema mexicano para as mocinhas - o qual, como já afirmamos, costumava coincidir com perfeição às regras presentes ainda hoje nos manuais de cinematografia.

No que tange aos filmes estrelados por Dolores del Río, a jovem indígena temente a Deus e aos homens que protagoniza María Candelaria recebe um tratamento fotográfico que segue as convenções supostamente mais adequadas para construir a imagem feminina. Em Las abandonadas, a visualidade de Margarita oscila entre a tradicional combinação mecanismos de suavização + luz difusa + branquitude + sombras cinza-claro e outros arranjos dos elementos fotográficos menos ortodoxos (algumas vezes, o sentido da mudança na fotografia é pleno, transparente; outras, não o é). Por fim, em La casa chica acompanhamos a triste história de Amalia, uma mulher que também é fotografada segundo as recomendações de Alton, Moura e tantos outros - mesmo expondo as contradições do ideal de família defendido nas produções do período.

Como explicar estes e tantos outros "desrespeitos"? Ao contrário do que indicam o senso comum e muitos dos manuais de cinematografia, nem a fotografia era estruturada apenas pelas questões de gênero, nem tais questões eram tão simples como parecem à primeira vista.

Destacamos anteriormente que uma das três principais características da fotografia cinematográfica clássica era a dramatização. Cabia ao diretor de fotografia contribuir com a onisciência e a reiteração da obra em seus vários níveis, exprimindo visualmente se determinada personagem era boa ou má, obediente ou rebelde; se o que ia acontecer em seguida era bom ou ruim, surpreendente ou não, etc.

O gênero, dentro da dramatização, era um dos aspectos mais importantes - logo, consistia em um eixo estruturante da fotografia de homens e mulheres. Todavia, não se pode ignorar que existiam outros. Ao menos nos longas-metragens aqui 
estudados, destacaríamos em pé de igualdade para a construção da visualidade o caráter e a narrativa.

De que maneira proceder para dramatizar diferentes elementos (que podem, inclusive, ser conflitantes) é algo que não é ensinado de um fotógrafo para o outro ou nos manuais -mesmo em memórias e relatos de diretores de fotografia este tipo de caso não costuma ser abordado -, até porque é muito difícil prever quais serão as características que precisarão ser equacionadas e em que intensidade elas aparecerão. Logo, caberá a cada DF elaborar a resposta que, por alguma razão, pareça a mais conveniente para aquele filme (fruição estética, adequação narrativa, exigência da star, do diretor ou do produtor).

Ademais, uma das grandes contribuições dos estudos feministas foi demonstrar que o sentido e a importância atribuídos às diferenças anatômicas que existem entre homens e mulheres são culturais e têm variado ao longo da história. Não existe, portanto, um entendimento único, universal e atemporal do feminino - e, na verdade, não existe nem a obrigatoriedade de um feminino - para nortear a construção visual de gênero que se exige nos manuais de cinematografia.

Ao destacar as singularidades do cinema mexicano clássico industrial frente à produção estadunidense realizada no mesmo período - uma reivindicação que não é feita de forma tacanha e considera as muitas semelhanças entre as cinematografias dos dois países - Julia Tuñón pondera:

Vejo originalidade neste cinema. Percebo que ele é muito diferente do estadunidense, referência obrigatória, no que se refere à concepção do amor, da mulher, do trabalho, etc. Diferentemente deste, naquele o amor homem-mulher não conduz à felicidade, como também não conduzem o trabalho ou a propriedade privada, porque tais princípios não correspondem à construção de gênero particular que predominava no México nestes anos. Observo que, na película, recria-se um arquétipo particular do mexicano, mais ligado às ideias de culpa e sacrifício que as de sucesso e eficiência. Nisso fica evidente a importância da cultura católica imperante. Vejo neste cinema sujeitos próprios do país, suas inquietações, rostos e reações. Recria-se a tendência ao sacrifício, à capacidade para aguentar desgraças, o mérito de sofrer com dignidade (TUÑÓN, 1998, p. 290). 
Percebe-se, portanto, que se a fotografia cinematográfica variava em função dos diferentes elementos a serem dramatizados, a missão do fotógrafo de seguir à risca as regras da "boa" direção de fotografia para a mulher se tornava ainda mais complicada devido às nuances que os contextos acarretavam em termos de gênero. Em determinada produção a amante ou a prostituta era ou não bondosa, pura e virtuosa? Após voltar a se vestir e a agir "como mulher", Catalina deveria receber novamente seu primeiro tratamento fotográfico? O arrependimento de Doña Bárbara seria suficiente para acabar com as enormes sombras que estiveram presentes em seu rosto durante quase toda a narrativa? Não existe uma única resposta, há tantas possibilidades quanto filmes que foram feitos. 
Desnaturalizar a técnica: contribuições feministas para pensar a direção de fotografia cinematográfica| Marina Cavalcanti Tedesco

\section{Referências}

ALTON, J. Painting with light. University of California Press: California: 1997.

BERGERY, B. Reflections: twenty-one cinematographers at work. Los Angeles: ASC Holding Corp, 2002.

BUTLER, J. "Corpos que pesam sobre os limites discursivos do sexo”. In: LOURO, G. L. (Org.). O corpo educado: pedagogias da sexualidade. Belo Horizonte: Autêntica, 1999. p.153-173.

CAMPOS, M. C. S. de S.; SILVA, V. L. G. da (org.). Feminização do magistério: vestígios do passado que marcam o presente. Bragança Paulista: EDUSF, 2002.

D’ALLONNES, F. R. La lumière au cinema. Paris: Editions Cahiers de cinema, 1991.

DE LA MORA, S. Cinemachismo. Masculinities and Sexuality in Mexican Film. Austin: University of Texas Press, 2006.

DE LAURETIS, T. “Imagenação”. In: Cadernos de pesquisa e debate do Núcleo de Estudo de Gênero da UFPR, Curitiba, UFPR, n. 2, p. 1-79, 2003.

DYER, R. White. Florence, KY: Taylor \& Francis Group, 1999.

FOUCAULT, Michel. História da sexualidade 1: a vontade de saber. Rio de Janeiro: Edições Graal, 1988.

HARAWAY, D. "Um manifesto para os cyborgs: ciência, tecnologia e feminismo socialista na década de 80". In: HOLLANDA, H. B. de (org.). Teorias e impasses - o feminismo como crítica da cultura. Rio de Janeiro: Rocco, 1994. p. 3, p. 243-288.

KRASILOVSKY, A. Women behind the camera: conversations with camerawomen. Westport, CT: Praeger Publishers, 1997. 
LAQUEUR, T. W. Making Sex: Body and Gender From the Greeks to Freud. Cambridge, MA: Harvard University Press, 1990.

McCARTHY, T. "Through a lens darkly: the life and films of John Alton". In: ALTON, J. Painting with light. University of California Press: California: 1997. p. IX-XXXIV.

MORIN, E. As estrelas: mito e sedução no cinema. Rio de Janeiro: José Olympio, 1989.

MOURA, E. 50 Anos Luz - Câmera e Ação. São Paulo: Editora Senac São Paulo, 2005.

MULVEY, L. "Prazer Visual e Cinema Narrativo". In:XAVIER, I. (org.). A experiência do cinema. Rio de Janeiro: Editora Graal, 1983. p. $437-454$.

NETO, A. L. da S. Dicionário de fotógrafos do cinema brasileiro. São Paulo: Imprensa Oficial do Estado de São Paulo, 2010.

SANTOS, M. A natureza do espaço: técnica e tempo, razão e emoção. São Paulo: Editora da Universidade de São Paulo, 2006.

SELLIER, G. A contribuição dos gender studies aos estudos fílmicos. Disponível: <http://www.unb.br/ih/his/gefem/ labrysl_2/sellierl.html>. Acesso em: 24/11/2013.

STAIGER, J. The Hollywood mode of production to 1930. In: BORDWELL, D.; STAIGER, J.; THOMPSON, K. The Classical Hollywood: Film Style E Mode of Production to 1960. Londres: Routledge, 1985. p. 85-153.

THOMPSON, K. "The formulation of the classical style, 190928". In: BORDWELL, D.; STAIGER, J. e THOMPSON, Kriston. The Classical Hollywood: Film Style \& Mode of Production to 1960. Londres: Routledge, 1985. p. 155-240.

TOLEDO, T. (org.). Realizadoras latinoamericanas/Latin American Women Filmmakers: cronología/chronology (1917- 
Desnaturalizar a técnica: contribuições feministas para pensar a direção de fotografia cinematográfica| Marina Cavalcanti Tedesco

1987). Nova Iorque: Círculo de Cultura Cubana, 1987.

TUÑ́́N, J. Mujeres de luz y sombra en el cine mexicano. La construcción de una imagen. 1939-1952. México, D.F.: El Colegio de México/Imcine, 1998.

\section{Filmografias}

Rebecca. Direção de Alfred Hitchcock, 1995. Preto e branco, legendado. (DVD)

Doña Bárbara. Direção de Fernando de Fuentes, 1943. Preto e branco, legendado. (DVD)

La monja alférez. Direção de Emilio Gómez Muriel, 1944. Preto e branco, legendado. (DVD)

Río Escondido. Direção de Emilio Fernández, 1947. Preto e branco, legendado. (DVD)

María Candelaria. Direção de Emilio Fernández, 1943. Preto e branco, legendado. (DVD)

Las abandonadas. Direção de Emilio Fernández, 1944. Preto e branco, legendado. (DVD)

La casa chica. Direção de Roberto Gavaldón, 1950. Preto e branco, legendado. (DVD)

Artigo recebido em março e aprovado em junho de 2014. 